\title{
Delayed diagnosis of Peutz-Jeghers syndrome due to pathological information loss or mistake in family/personal history
}

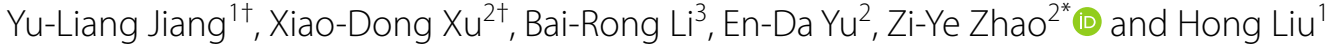

\begin{abstract}
Objective: To report Peutz-Jeghers syndrome (PJS) cases with non-definitive clues in the family or personal history and finally diagnosed through pathological examination and STK11 gene mutation test.

Clinical presentation and intervention: PJS was suspected in 3 families with tortuous medical courses. Two of them had relatives departed due to polyposis or colon cancer without pathological results, and the other one had been diagnosed as hyperplastic polyposis before. Diagnosis of PJS was confirmed by endoscopy and repeated pathological examinations, and the STK11 mutation test finally confirmed the diagnosis at genetic level, during which 3 novel mutation were detected (536C > A, 373_374insA, 454_455insGGAGAAGCGTTTCCCAGTGTGCC).
\end{abstract}

Conclusion: Early diagnosis of PJS is important and may be based on a family history with selective features among family members, and the pathological information is the key. The novel mutations also expand the STK11 variant spectrum.

Keywords: Peutz-Jeghers syndrome, STK11 gene, Hamartoma, Polyposis, Enteroscopy

\section{Introduction}

Peutz-Jeghers syndrome (PJS; OMIM 175,200), an autosomal dominant disorder, is caused by germline mutations in the serine/threonine kinase 11 (STK11) gene. More than 400 associated gene mutations (Human Gene Mutation Database, HGMD; http://www.hgmd.cf.ac.uk) have been identified. The clinical features of PJS include gastrointestinal (GI) hamartomatous polyps, mucocutaneous pigmentation (MP), and an increased risk of GI and extra-GI malignancies [1]. Although most reported cases are in adults, over $30 \%$ of patients are younger than 10 [2]. Timely diagnosis is important because PJS can cause severe complications such as bowel obstruction

\footnotetext{
*Correspondence: yemenzhao@126.com

${ }^{\dagger}$ Yu-Liang Jiang and Xiao-Dong Xu have contributed equally to this work.

${ }^{2}$ Department of Colorectal Surgery and Hereditary Colorectal Cancer Registry, Changhai Hospital, 168 Changhai Rd., Shanghai 200433, China

Full list of author information is available at the end of the article
}

in young patients due to GI polyps and PJS-associated tumors, which are rare but do exist $[3,4]$. The fact that many PJS patients lack a family history of the disorder makes diagnosis more difficult, and a family history is not always obvious in others. Sometimes, making a correct pathological diagnosis of hamartoma is not a matter of course.

Establishing polyposis registry is the international advanced mode in polyposis management, and Shiji$\tan$ Polyposis Registry was established in 2020. In the reported cases, which were collected in our registry, a family history or a personal history was present but not recognized or misidentified. Finally, a prudent doctor considered the condition comprehensively and made a final diagnosis of PJS. Moreover, STK11 mutation detection helped distinguish the variant carriers in the next generation.

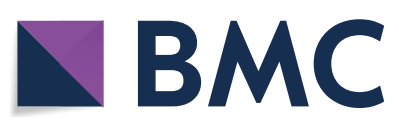

(c) The Author(s) 2021. Open Access This article is licensed under a Creative Commons Attribution 4.0 International License, which permits use, sharing, adaptation, distribution and reproduction in any medium or format, as long as you give appropriate credit to the original author(s) and the source, provide a link to the Creative Commons licence, and indicate if changes were made. The images or other third party material in this article are included in the article's Creative Commons licence, unless indicated otherwise in a credit line to the material. If material is not included in the article's Creative Commons licence and your intended use is not permitted by statutory regulation or exceeds the permitted use, you will need to obtain permission directly from the copyright holder. To view a copy of this licence, visit http://creativecommons.org/licenses/by/4.0/. The Creative Commons Public Domain Dedication waiver (http://creativeco mmons.org/publicdomain/zero/1.0/) applies to the data made available in this article, unless otherwise stated in a credit line to the data. 


\section{Clinical report \\ Case 1}

The proband is an 18-year-old male from East China. When he was 11 years old, a local doctor noticed MP (around his mouth and on his fingertips) during a routine examination. His father also had similar MP since birth, and the patient's elder sister died of serious polyposis when she was 15 years old. Discovering this information, the doctor suspected PJS and referred him for a colonoscopy, during which several colon polyps were discovered and resected. Pathological examination of the polyps revealed that they were hamartomas, confirming the diagnosis of PJS. The father was also referred for a colonoscopy which revealed hamartomatous polyps, proving that he also had PJS. The patient's deceased sister had died from serious polyposis and most likely had PJS, since they recalled that she also had MP. No other relatives had features of PJS (Fig. 1a). The proband then developed abdominal distention several times and were referred to our center for suspected intussusception based on abdominal plain film findings. Therefore, we performed double-balloon enteroscopy (DBE), during which two large jejunal polyps $(5 \mathrm{~cm}$ in diameter) and several small polyps were discovered within the small bowel and ascending colon; the two large polyps were resected endoscopically. Other polyps were resected using DBE during his surveillance.

\section{Case 2}

The 2nd proband is a 50-year-old female with oral MP from North China, who is adopted and her biological parents' information is unavailable. She went for a doctor in a local hospital due to weight loss, anemia and recurrent hematochezia, and underwent gastroscopy at the age of 40, during which large number of polyps were detected. The patient refused to go for a surgeon at that moment, but two years later, a laparotomy and colectomy was not avoided. Two large polyps whose biggest diameter was $4 \mathrm{~cm}$ were pathologically dissected and diagnosed as "hyperplastic polyp". Another 2 years later, the patient went to a tertiary teaching hospital for endoscopy, and the correct pathological diagnosis of hamartoma and PJS was finally made. Her younger daughter also has MP and gastric polyps.

\section{Case 3}

The 3rd proband is a 38-year-old male from South China. Before he was finally diagnosed as PJS, there were two relatives in his family who were suspected as PJS, and all the suspect individuals in the family have MP. His father was diagnosed as colon cancer and concurrent ileus at 45 years, and died the same year without operative treatment. The proband's eldest brother died of massive lower GI bleeding at the age of 19. Unfortunately, these two relatives died without any evidence of intestinal polyposis or pathological diagnosis. In 2005, the proband developed acute upper GI bleeding and was sent to emergency center. After subtotal gastrectomy, several polyps were resected and pathologically diagnosed as hamartomas. Finally, the diagnosis of PJS was made, and the proband's elder brother was also diagnosed through endoscopy. Moreover, the sons of the proband and his elder brother are highly suspected due to their MPs, though they have not received endoscopy. The pedigrees of the three families are showed in Fig. 1a.

\section{Mutation detection}

During the patient's hospitalization or interview, we recruited them into the Polyposis Surveillance and Research Program, and blood or oral mucosa samples were collected from the probands and their available family members and were screened using an animal genomic DNA kit (TSP201, TsingKe Biotech, Beijing, China), according to the manufacturer's instructions. Blood samples of 50 unrelated control individuals seen in our department for gastric polyps during September 2016 were also screened. All biological samples were collected after informed consent was obtained. Genomic DNA of peripheral blood leukocytes or oral mucosa cells was extracted, and all nine coding exons of the STK11 gene were amplified by polymerase chain reaction (PCR) using a $2 \times$ modified DNA polymerase mix (TSE004, TsingKe Biotech, Beijing, China) and then sequenced. The extraction, PCR and sequencing experiments were performed in DiagRe Biotech Co. Ltd. (Shanghai, China) and Map Biotech Co. Ltd. (Shanghai, China). The details of the methods and the primer sequences have been reported previously (Additional file 1: Table S1) [5].

Three heterozygous germline mutations were detected in the samples of the probands and available patients respectively (Fig. 1b, e); whereas, the

\footnotetext{
(See figure on next page.)

Fig. 1 Pedigrees and genetic information on the PJS families. a The genograms (Squares= males, and circles= females; left half black symbols = mucocutaneous pigmentation, quart-pink= cancer, and quart-red =LGIB; $E=$ examination and $\pm=$ positive/negative; an oblique line indicates a deceased individual; the index patient is indicated by an arrow.) b The structure of the STK11 gene and the location of the 3 mutations are showed. For c.536C > A, c PolyPhen-2 score for this mutation is 1.000 , indicating that it is probably damaging. AND (d) the local structures around the mutation site of the wild-type and mutant STK11 proteins generated by Swiss-model online software show obvious differences. $\mathbf{e}$ Sanger sequencing revealed 3 heterozygous mutations. LGIB lower gastrointestinal bleeding
} 
A
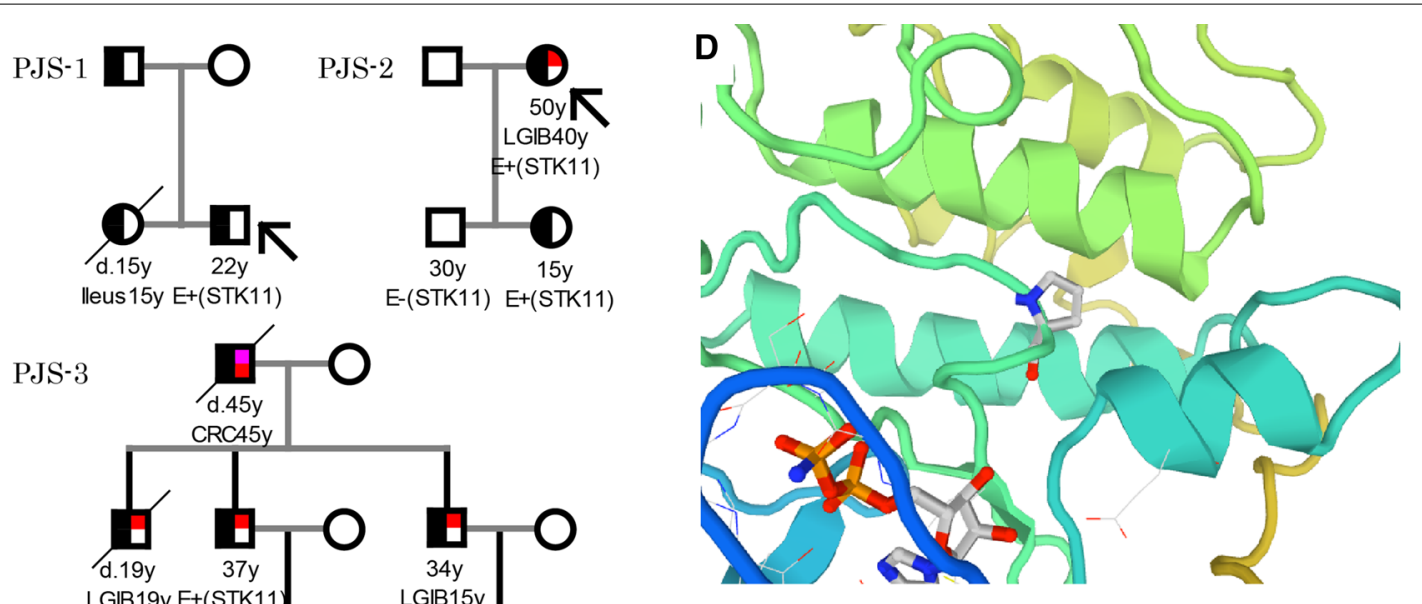

PJS-3 $\underset{\substack{\text { d.45y } \\ \text { CRC45y }}}{ } \mathbf{O}$
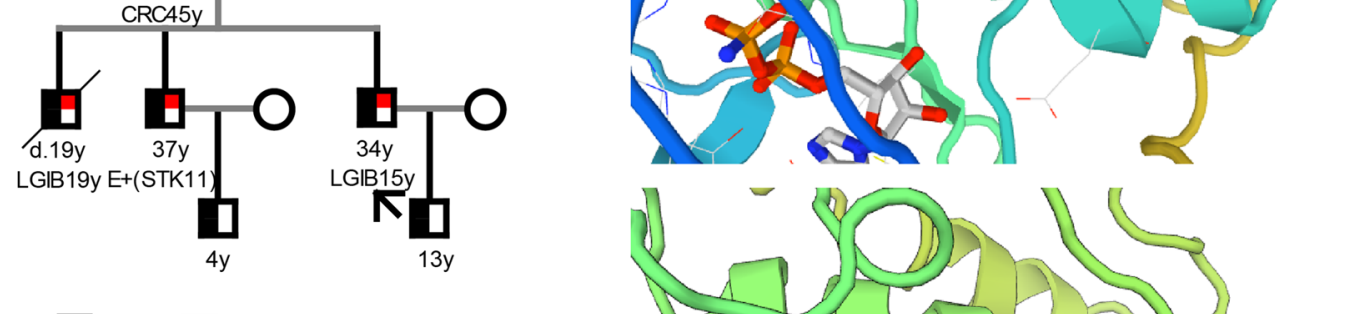

B $\square^{N \text {-terminal }} \square \begin{aligned} & \text { Kinase } \\ & \text { domain }\end{aligned}$ C-terminal

c.454_455insGGAGAAGCGTTTCCCAGTGTGCC c.373_374insA \)

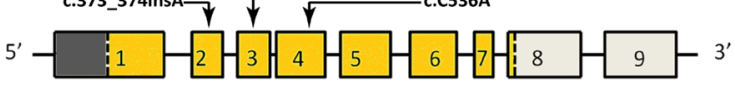

C
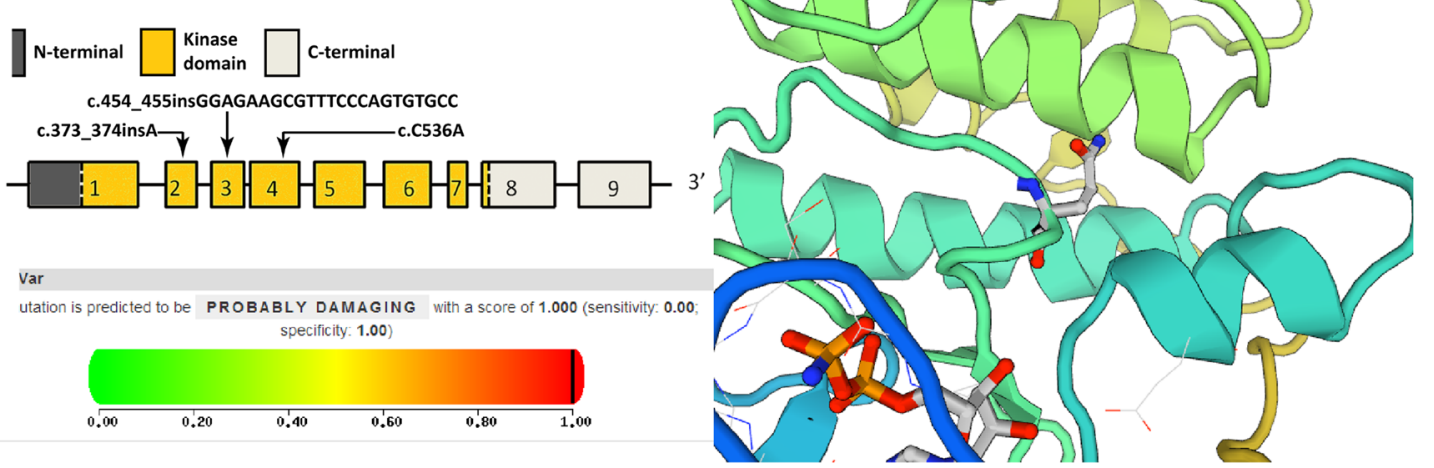

E \begin{tabular}{l}
$\perp$ C A T \\
\hline
\end{tabular} Wild-type

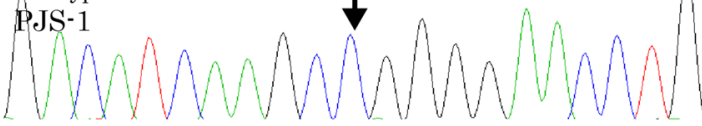
codon 179, Pro
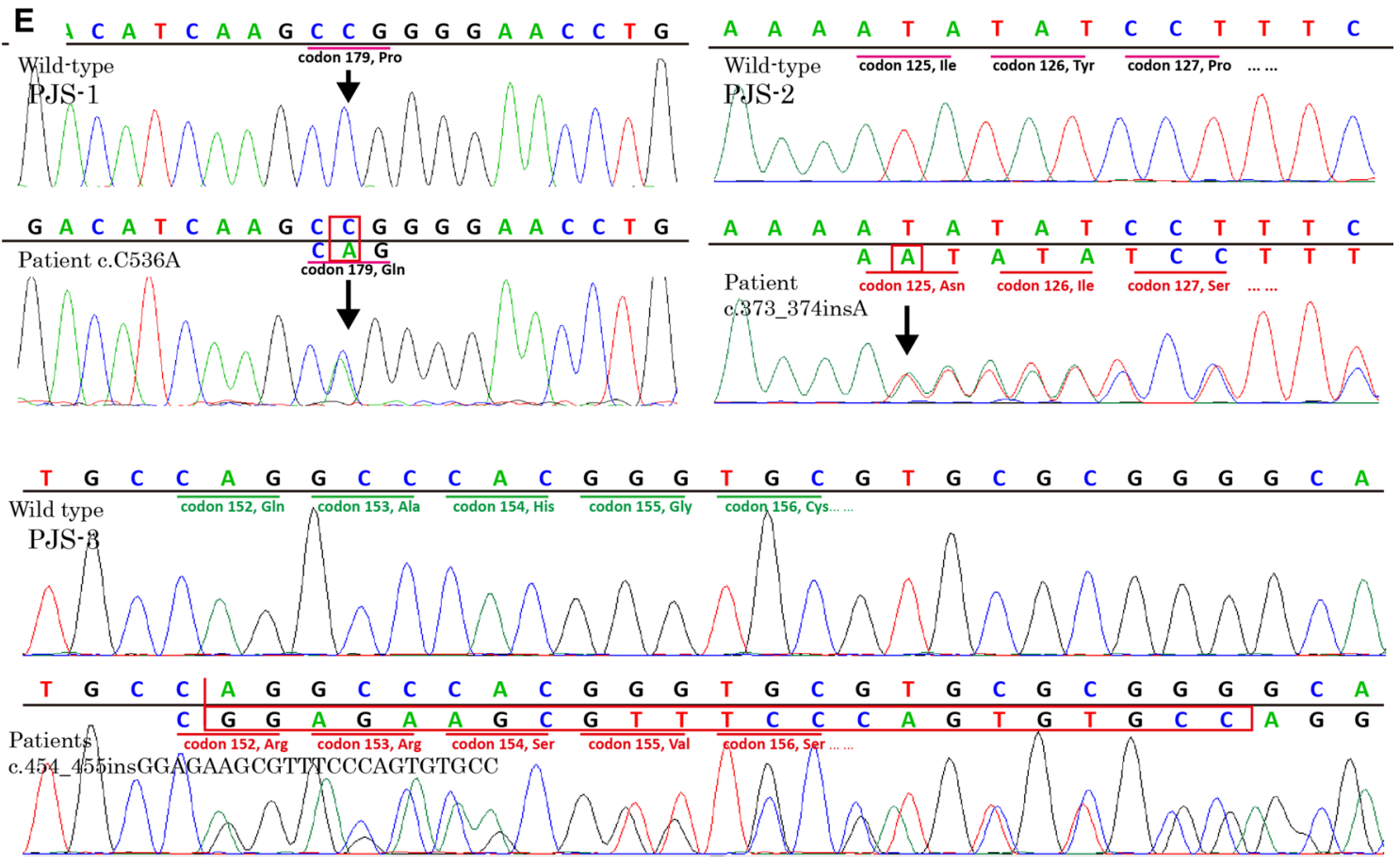
Table 1 STK11 Mutation detected in the probands

\begin{tabular}{lllll}
\hline Family & Exon & Nucleotide & $\begin{array}{l}\text { Amino acid } \\
\text { change/ } \\
\text { effect }\end{array}$ & Documented \\
\hline PJS-1 & 4 & 536C>A & P179Q & No \\
PJS-2 & 2 & $\begin{array}{l}\text { 373_374insA } \\
\text { 454_455insGGAGAAGC } \\
\text { PJS-3 }\end{array} 3$ & Q152Rfs*17 & No \\
& & GTTCCAGTGTGCC & & No \\
\hline
\end{tabular}

Table 2 Classification of multiple evidences about STK11 c.536C > A

\begin{tabular}{|c|c|}
\hline Evidences & c.536C > A (p.P179Q) \\
\hline Population data & Absent in 50 controls and population databases (ExAC) (PM2) \\
\hline Computational and predictive data & $\begin{array}{l}\text { Multiple lines of computational evidence support a deleteri- } \\
\text { ous effect on the gene or gene product (conservation, } \\
\text { evolutionary, splicing impact, etc.) (PP3) }\end{array}$ \\
\hline Functional data & $\begin{array}{l}\text { Missense variant in a gene that has a low rate of benign } \\
\text { missense variation and in which missense variants are a } \\
\text { common mechanism of disease (PP2) }\end{array}$ \\
\hline Segregation data & Cosegregation with PJS (PP1) \\
\hline De novo data & Not available \\
\hline Other data & Patient's phenotype highly specific for gene (PP4) \\
\hline Conclusion & Likely pathogenic (1 PMs and 4 PPs) \\
\hline
\end{tabular}

\section{Discussion}

PJS was reported by Dr. Connor first in 1895 [9], and then Dr. Jeghers identified the coexistence of MP and GI polyposis as a distinct clinical entity [10]. Based on clinical observations, it is sometimes difficult to identify PJS in a timely manner due to its incomplete penetrance and a varied age of onset. In the families reported here, the father in PJS-1 family had MP without GI symptoms, such that he was not diagnosed until he underwent colonoscopy in his $40 \mathrm{~s}$; whereas, the elder sister died of 
STK11 (OMIM 602,216) has been considered a pathogenic gene since 1997 [16], and various mutation types can cause PJS, such as point mutations (missense and nonsense), indel mutations [17] and large defection [18]. By the combining use of Sanger sequencing and multiplex ligation-dependent probe amplification (MLPA), the detection rate of STK11 mutation in PJS patient becomes very high $[19,20]$, and we have got a detection rate of 73.5\% in Chinese cohort [21]. The STK11 protein is comprised of three functional domains [22]; most of the reported mutations are located in the catalytic kinase domain and result in absent kinase activity or disrupted formation of the kinase complex [23]. These 3 novel mutations are also located in this area, likely resulting in a key structure change that impairs kinase activity and give rise to the clinical features of PJS. They were not found in healthy relatives or in 50 unrelated control individuals, and clearly co-segregated with the disease phenotype in the families. Together with structure and function prediction results, we conclude that two frameshift mutations are disease-specific and the missense variant is likely pathological.

\section{Conclusion}

We identified 3 novel heterozygous mutations in STK11 gene shown to cause PJS in Chinese families in which the diagnosis was delayed due to pathological information loss or mistake in family or personal history. Identification of the pathogenic variants expands the mutation spectrum of PJS and emphasizes the variety of clinical features seen and the importance of early diagnosis and surveillance for PJS patients.

\section{Abbreviations}

DBE: Double-balloon enteroscopy; Gl: Gastrointestinal; HGMD: Human Gene Mutation Database; MLPA: Multiplex ligation-dependent probe amplification; MP: Mucocutaneous pigmentation; PCR: Polymerase chain reaction; PJS: Peutz-Jeghers syndrome; STK11: Serine/threonine kinase 11.

\section{Supplementary Information}

The online version contains supplementary material available at https://doi. org/10.1186/s13023-021-01900-7.

Additional file 1. Table S1. Primers used for STK11 exons amplification and sequencing.

Additional file 2. Fig S1. Evolutionary conservation of amino acid residues altered by c.536C>A (p. P179Q) across different species.

\section{Acknowledgements}

We thank all the subjects for their participation. We thank Prof. NING Shou-Bin from Airforce Medical Center and his team for their effort in PJS treatment and research. We also appreciate Dr. Geng Qiu and Ms. Xin Chen from DiagRe LLC for their help with sample collection and experiments.

\section{Authors' contributions}

YJ collected and analyzed the patient data regarding clinical process. ZZ was in charge of data presenting, analyzing and manuscript writing. BL helped with the clinical examination. EY provided the senior advises and reviews the manuscript. XX and HL provided the research resources and supervised the study. All authors read and approved the final manuscript.

\section{Funding}

This work was supported by National Key R\&D Program of China

(2017YFC1308800), Science and Technology Support Program (Medicine Guidance) of Shanghai S\&T Committee (124119A4400), National Natural Science Foundation of China (81870455) and Shijitan Hospital Foundation for Young Scholars (2019-q09).

\section{Availability of data and material}

The data that supports the findings of this study are available in the supplementary material of this article.

\section{Declarations}

Ethics approval and consent to participate

All procedures performed in this study that involved human participants were in accordance with the ethical standards of the Medical Ethics Committee of Beijing Shijitan Hospital and with the 1964 Helsinki declaration and its later amendments or comparable ethical standards. The legal guardians of the proband and the adult participants agreed to participate in this study with written informed consent.

\section{Consent for publication}

Written consent was obtained from the legal guardian of the proband and the adult participants themselves.

\section{Competing interests}

The authors declare that they have no competing interests.

\section{Author details}

${ }^{1}$ Department of Gastroenterology, Beijing Shijitan Hospital, Capital Medical University, 10 Tieyi Rd., Beijing 100038, China. ${ }^{2}$ Department of Colorectal Surgery and Hereditary Colorectal Cancer Registry, Changhai Hospital, 168 Changhai Rd., Shanghai 200433, China. ${ }^{3}$ Department of Gastroenterology, Airforce Medical Center of PLA, Beijing 100142, China.

Received: 25 April 2020 Accepted: 29 May 2021

Published online: 08 June 2021

\section{References}

1. Giardiello FM, Brensinger JD, Tersmette AC, et al. Very high risk of cancer in familial Peutz-Jeghers syndrome. Gastroenterology. 2000;1 19:1447-53.

2. Huang ZH, Song Z, Zhang P, et al. Clinical features, endoscopic polypectomy and STK1 1 gene mutation in a nine-month-old Peutz-Jeghers syndrome Chinese infant. World I Gastroenterol. 2016;22:3261-7.

3. Massa G, Roggen N, Renard M, et al. Germline mutation in the STK11 gene in a girl with an ovarian Sertoli cell tumour. Eur J Pediatr. 2007;166:1083-5.

4. Tsai $\mathrm{HL}$, Lin $\mathrm{CH}$, Cheng $\mathrm{YL}$, et al. Rectal carcinoma in a young female patient with Peutz-Jeghers syndrome: a case report. Med Princ Pract. 2014;23:89-91.

5. Zhao ZY, Jiang YL, Li BR, et al. A 23-nucleotide deletion in STK11 gene causes Peutz-Jeghers syndrome and malignancy in a Chinese patient without a positive family history. Dig Dis Sci. 2017;62:3014-20.

6. Biasini M, Bienert S, Waterhouse A, et al. SWISS-MODEL: modelling protein tertiary and quaternary structure using evolutionary information. Nucleic Acids Res. 2014;42:W252-8.

7. Vaser R, Adusumalli S, Leng SN, et al. SIFT missense predictions for genomes. Nat Protoc. 2016;11:1-9.

8. Richards S, Aziz N, Bale S, et al. Standards and guidelines for the interpretation of sequence variants: a joint consensus recommendation of the 
American College of Medical Genetics and Genomics and the Association for Molecular Pathology. Genet Med. 2015;17:405-24.

9. Giardiello FM, Trimbath JD. Peutz-Jeghers syndrome and management recommendations. Clin Gastroenterol Hepatol. 2006;4:408-15.

10. Jeghers $\mathrm{H}, \mathrm{Mc} \mathrm{KV}$, Katz KH. Generalized intestinal polyposis and melanin spots of the oral mucosa, lips and digits; a syndrome of diagnostic significance. N Engl J Med. 1949:241:993.

11. van Lier MG, Mathus-Vliegen EM, Wagner A, et al. High cumulative risk of intussusception in patients with Peutz-Jeghers syndrome: time to update surveillance guidelines? Am J Gastroenterol. 2011;106:940-5.

12. Beggs $A D$, Latchford $A R$, Vasen $H F$, et al. Peutz-Jeghers syndrome: a systematic review and recommendations for management. Gut. 2010:59:975-86.

13. Burke CA, Santisi J, Church J, et al. The utility of capsule endoscopy small bowel surveillance in patients with polyposis. Am J Gastroenterol. 2005;100:1498-502

14. Zhang ZC, Li BR, Li X, et al. Location, growth and clinical outcome of polyps of patients with Peutz-Jeghers syndrome. Chin J Digest. 2016;36:593.

15. Jiang $Y L$, $Z$ hao $Z Y, L i B R$, et al. Early screening the small bowel is key to protect Peutz-Jeghers syndrome patients from surgery: a novel mutation c.243delG in STK11 gene. BMC Gastroenterol. 2019;19:70.

16. Hemminki A, Tomlinson I, Markie D, et al. Localization of a susceptibility locus for Peutz-Jeghers syndrome to 19p using comparative genomic hybridization and targeted linkage analysis. Nat Genet. 1997;15:87-90.

17. Chen JH, Zheng JJ, Guo Q, et al. A novel mutation in the STK11 gene causes heritable Peutz-Jeghers syndrome-a case report. BMC Med Genet. 2017;18:19.
18. Jang MS, Lee YM, Ko BM, et al. Complete STK11 Deletion and Atypical Symptoms in Peutz-Jeghers Syndrome. Ann Lab Med. 2017;37:462-4

19. Yang HR, Ko JS, Seo JK. Germline mutation analysis of STK11 gene using direct sequencing and multiplex ligation-dependent probe amplification assay in Korean children with Peutz-Jeghers syndrome. Dig Dis Sci. 2010;55:3458-65.

20. Orellana P, Lopez-Kostner F, Heine C, et al. Large deletions and splicingsite mutations in the STK11 gene in Peutz-Jeghers Chilean families. Clin Genet. 2013;83:365-9.

21. Jiang YL, Zhao ZY, Li BR, et al. STK11 gene analysis reveals a significant number of splice mutations in Chinese PJS patients. Cancer Genet. 2019:230:47-57.

22. Hanks SK, Quinn AM, Hunter T. The protein kinase family: conserved features and deduced phylogeny of the catalytic domains. Science. 1988;241:42-52.

23. Boudeau J, Baas AF, Deak M, et al. MO25alpha/beta interact with STRADalpha/beta enhancing their ability to bind, activate and localize LKB1 in the cytoplasm. EMBO J. 2003;22:5102-14.

\section{Publisher's Note}

Springer Nature remains neutral with regard to jurisdictional claims in published maps and institutional affiliations.
Ready to submit your research? Choose BMC and benefit from:

- fast, convenient online submission

- thorough peer review by experienced researchers in your field

- rapid publication on acceptance

- support for research data, including large and complex data types

- gold Open Access which fosters wider collaboration and increased citations

- maximum visibility for your research: over 100M website views per year

At BMC, research is always in progress.

Learn more biomedcentral.com/submissions 